\title{
ScienceDirect
}

\section{Application of thermal battery in the ice storage air-conditioning system as a subcooler}

\author{
Ming-Chao Huang ${ }^{\mathrm{a}}$, Bo-Ren Chen ${ }^{\mathrm{b}}$, Ming-Jer Hsiao ${ }^{\mathrm{a}}$, Sih-Li Chen ${ }^{\mathrm{b}, *}$ \\ ${ }^{a}$ Department of Electrical Engineering, Nan-Kai Institute of Technology, No.568 Chung Cheng Road, Tsao Tun, \\ Nan Tou, Taiwan 54243, ROC \\ ${ }^{\mathrm{b}}$ Department of Mechanical Engineering, National Taiwan University, No.1, Sec.4 Roosevelt Road, Taipei, Taiwan 10617, ROC
}

Received 23 March 2006; received in revised form 4 July 2006; accepted 24 July 2006

Available online 22 November 2006

\begin{abstract}
This article experimentally investigates the thermal performance of a thermal battery used in the ice storage air-conditioning system as a subcooler. The thermal battery utilizes the superior heat transfer characteristics of two-phase closed thermosyphon and eliminates the drawbacks found in convectional energy storage systems. Experimental investigations are first conducted to study the thermal behavior of thermal battery under different charge temperatures $\left(-5^{\circ} \mathrm{C}\right.$ to $\left.-9{ }^{\circ} \mathrm{C}\right)$ in which water is used as the energy storage material. This study also examines the thermal performance of the subcooled ice storage air conditioner under different cooling loads. Experimental data of temperature variation of water, ice fraction, refrigerant mass flow rate and coefficient of performance (COP) are obtained. The results show that supercooling phenomenon appears in the water and it can be ended when the charge temperature is lower than $-6{ }^{\circ} \mathrm{C}$. The system gives $28 \%$ more cooling capacity and $8 \%$ higher COP by the contribution of the thermal battery used as a subcooler.
\end{abstract}

(c) 2006 Elsevier Ltd and IIR. All rights reserved.

\section{Système de conditionnement d'air utilisé en tant que sous-refroidisseur: application de l'accumulation de glace}

Mots clés : Conditionnement d'air ; Accumulation thermique ; Bac à glace ; Expérimentation ; Sous-refroidissement

\section{Introduction}

Ice storage air-conditioning system $[1,2]$ is an important element of many energy conservation programs in industry

\footnotetext{
* Corresponding author. Tel.: +886 2 23631808; fax: +886 2 23631755 .

E-mail address: slchen01@ntu.edu.tw (S.-L. Chen).
}

and in commercial applications. Most of the ice storage systems utilize an active control method to store or release thermal energy. In the system design of thermal storage, a pump is included to transfer thermal energy from a high-temperature heat source to the thermal storage tank via flowing working fluid. To utilize the storage energy, an electromagnetic valve is used under control to change the flow path of the working fluid, so that the energy stored in the tank is released for use later. There are two drawbacks found in such systems. First, 


\begin{tabular}{llll} 
Nomenclature & \\
COP & $\begin{array}{l}\text { coefficient of performance of the system with } \\
\text { subcooler }(\text { dimensionless) }\end{array}$ & \multicolumn{2}{l}{ Greek symbol } \\
& density $\left(\mathrm{kg} \mathrm{m}^{-3}\right)$ \\
$C_{\mathrm{p}}$ & specific heat $\left(\mathrm{kJ} \mathrm{kg}^{-1}{ }^{\circ} \mathrm{C}\right)$ & $\rho$ & Subscripts \\
$H$ & water level height $(\mathrm{m})$ & $\mathrm{a}$ & outdoor unit \\
$h_{\mathrm{e}}$ & latent heat of water $\left(\mathrm{kJ} \mathrm{kg}{ }^{-1}\right)$ & $\mathrm{b}$ & thermal battery \\
$h$ & enthalpy $\left(\mathrm{kJ} \mathrm{kg}{ }^{-1}\right)$ & $\mathrm{c}$ & charge heat exchanger \\
$L_{x}$ & thermal battery width $(\mathrm{m})$ & $\mathrm{d}$ & discharge heat exchanger \\
$L_{y}$ & thermal battery length $(\mathrm{m})$ & $\mathrm{e}$ & energy storage material \\
$M$ & total mass of the energy storage material $(\mathrm{kg})$ & $\mathrm{i}$ & inlet \\
$m$ & mass $(\mathrm{kg})$ & 1 & cooling load \\
$P$ & pressure $(\mathrm{MPa})$ & $n$ & level no. of water \\
$\dot{Q}_{\mathrm{a}}$ & cooling capacity $(\mathrm{kW})$ & $\mathrm{o}$ & outlet \\
$\dot{Q}_{\mathrm{b}}$ & cold storage rate $(\mathrm{kW})$ & $\mathrm{s}$ & solid \\
$\dot{Q}_{1}$ & cooling load $(\mathrm{kW})$ & $\mathrm{t}$ & time \\
$r$ & mass flow ratio of the refrigerant & $\mathrm{w}$ & water \\
& (dimensionless) & &
\end{tabular}

the thermal storage shall be unusable in case of pump or electromagnetic valve failure. Second, the charge and discharge function of the conventional storage systems basically relies on the system piping design, and therefore only two functions, energy store and energy release, are available in its operating modes.

The present article provides a new ice storage design thermal battery [3] in which a passive type of control is adopted to eliminate drawbacks in the convectional ice storage systems. The thermal battery, as shown in Fig. 1, mainly includes an energy storage tank and a two-phase closed thermosyphon. The energy storage tank is filled with water. The thermosyphon includes three parts, namely, a group of parallel-fin tubes vertically disposed inside the energy storage tank, charge heat exchanger and discharge heat exchanger in a double-pipe type separately located at the upper and lower regions, respectively inside the storage tank. An adequate amount of working fluid (R-22) is filled in the thermosyphon.

Fig. 2a shows the function in which the system operates to store thermal (cold) energy. When low-temperature fluid
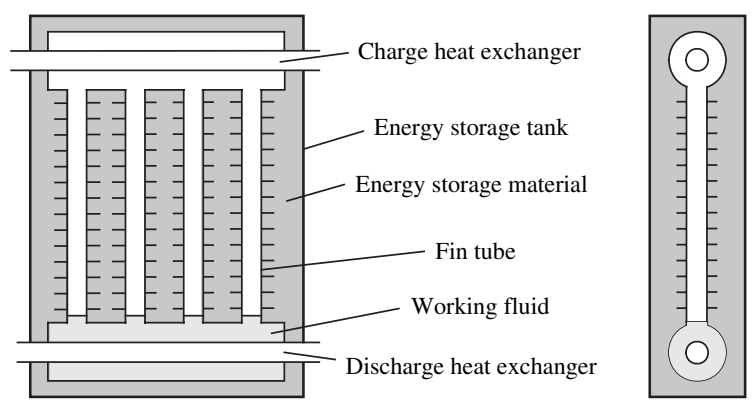

Fig. 1. Diagram of the thermal battery. flows into the charge heat exchanger, thermal energy contained in the water is transferred to the working fluid inside the parallel-fin tubes. The liquid working fluid undergoes film evaporation and absorbs thermal energy to solidify the water as ice in the storage tank. The vapor flows upward due to its buoyancy to the charge heat exchanger. As the thermal energy is transferred to the low-temperature fluid, the vapor working fluid undergoes film condensation on the outside surface of the charge heat exchanger. Then the condensate flows along the wall of parallel-fin tubes to complete the charge cycle.

Fig. $2 b$ illustrates the manner in which the system operates to release cold energy. When high-temperature fluid flows into the discharge heat exchanger, the ice inside the storage tank will absorb thermal energy to cool the hightemperature fluid. The liquid working fluid in the thermosyphon absorbs thermal energy from the high-temperature fluid through the discharge heat exchanger and gets boiled to produce vapor working fluid. The vapor flows upward and undergoes film condensation on the inner wall of the vertical fin tubes to release thermal energy to melt the ice. Then, the condensed working fluid flows downward and returns to the discharge heat exchanger to complete the discharge cycle.

The above-described charge and discharge operation modes work separately at different times. The third operation mode combines the above two operation modes, that is, the thermal battery also allows the operation of energy storage and energy release at the same time. As shown in Fig. 3a, when the cold energy supplied by the low-temperature flowing fluid is higher than that to be absorbed by the hightemperature flowing fluid, the thermal battery transfers the cold energy from the low-temperature fluid to the hightemperature fluid. Extra cold energy is stored inside the 
(a)

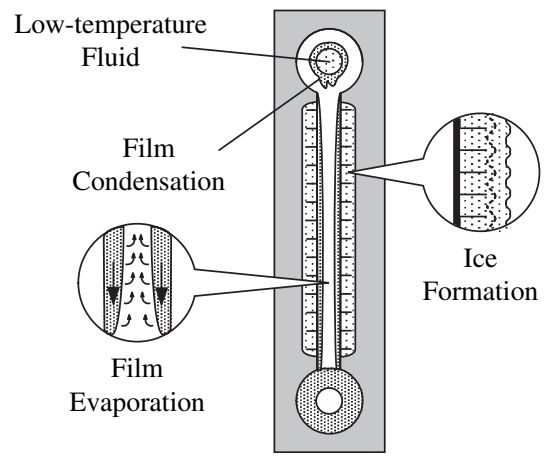

(b)

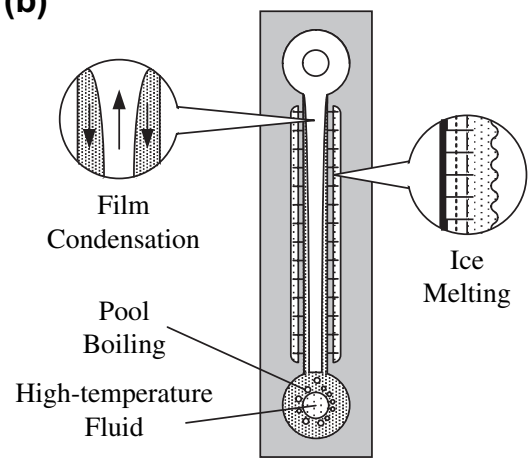

Fig. 2. Thermal storage in the thermal battery (a) charge mode, (b) discharge mode.

thermal battery. The heat transfer mechanisms in this case include film condensation in the charge heat exchanger, film evaporation along the thermosyphon tubes, pool boiling in the discharge heat exchanger, and ice formation along the fins. Fig. $3 b$ shows that as the energy supplied by the lowtemperature flowing fluid is not sufficient to cool the hightemperature fluid, cold energy can be released from the thermal battery to provide the high-temperature fluid to meet its need. The heat transfer mechanisms are similar to the above case except that film condensation occurs along the thermosyphon tubes and ice melts around the fins. When the cold energy supplied by the low-temperature fluid is equal to the energy absorbed by the high-temperature fluid, the thermal energy will be transferred directly from the discharge heat exchanger to the charge heat exchanger, as shown in Fig. 3c, through film condensation and pool boiling.

Chieh et al. [3] experimentally and theoretically studied the thermal behavior of the thermal battery during cold storage process. The charge and discharge heat exchangers are located at outside of the storage tank. As the system operates in charge or discharge mode, the heat exchanger combines the fin tubes as a two-phase closed loop thermosyphon. It shows that different heat transfer mechanisms including nucleate boiling, geyser boiling and natural convection are identified in different experimental systems with various working fluid fill levels. Higher working fluid fill level provides greater surface area for nucleate boiling. However, it decreases the effective condenser area for the discharge process. In this study, the charge and discharge heat exchangers are modified as a two-phase closed thermosyphon. The charge and discharge heat exchangers with double-pipe types are located at the upper and lower regions inside the storage tank, respectively. As the thermal battery stores or releases cold energy, the heat exchangers connect the fin tubes to form a two-phase closed thermosyphon, which enhances the effective film condensation and film evaporation areas and provides a more compact storage tank.

\section{Subcooled ice storage air-conditioning system}

Fig. 4 shows an ice storage air-conditioning system, which adopts the thermal battery as a subcooler. The system consists of an outdoor unit, a thermal battery, a plate heat exchanger, a fan-coil unit, a pressure-reducing valve, two expansion valves, and two solenoid valves. The outdoor unit includes a compressor and a condenser. The outdoor unit outlet connects to the inlet of charge and discharge heat exchangers individually. The outlet of charge heat
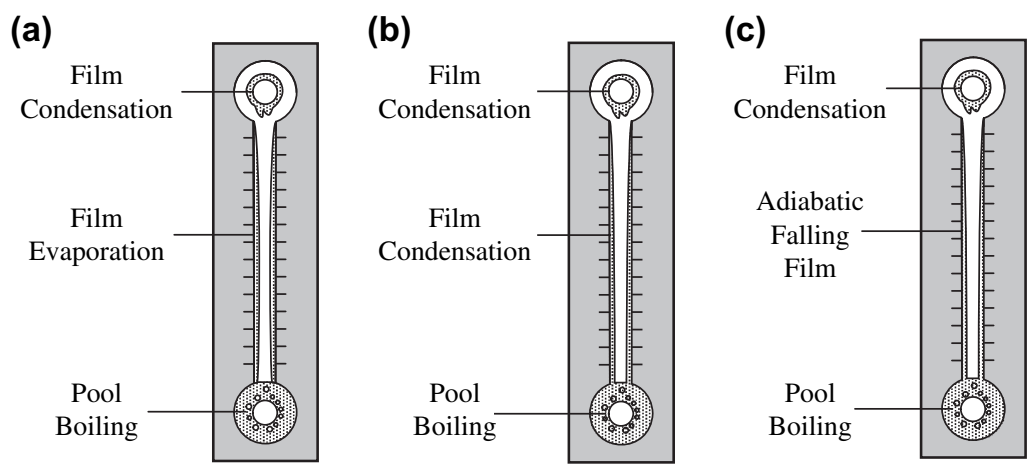

Fig. 3. Thermal storage in the thermal battery for the case of supplied cold energy (a) greater than the absorbed energy, (b) less than the absorbed energy, and (c) equal to the absorbed energy. 


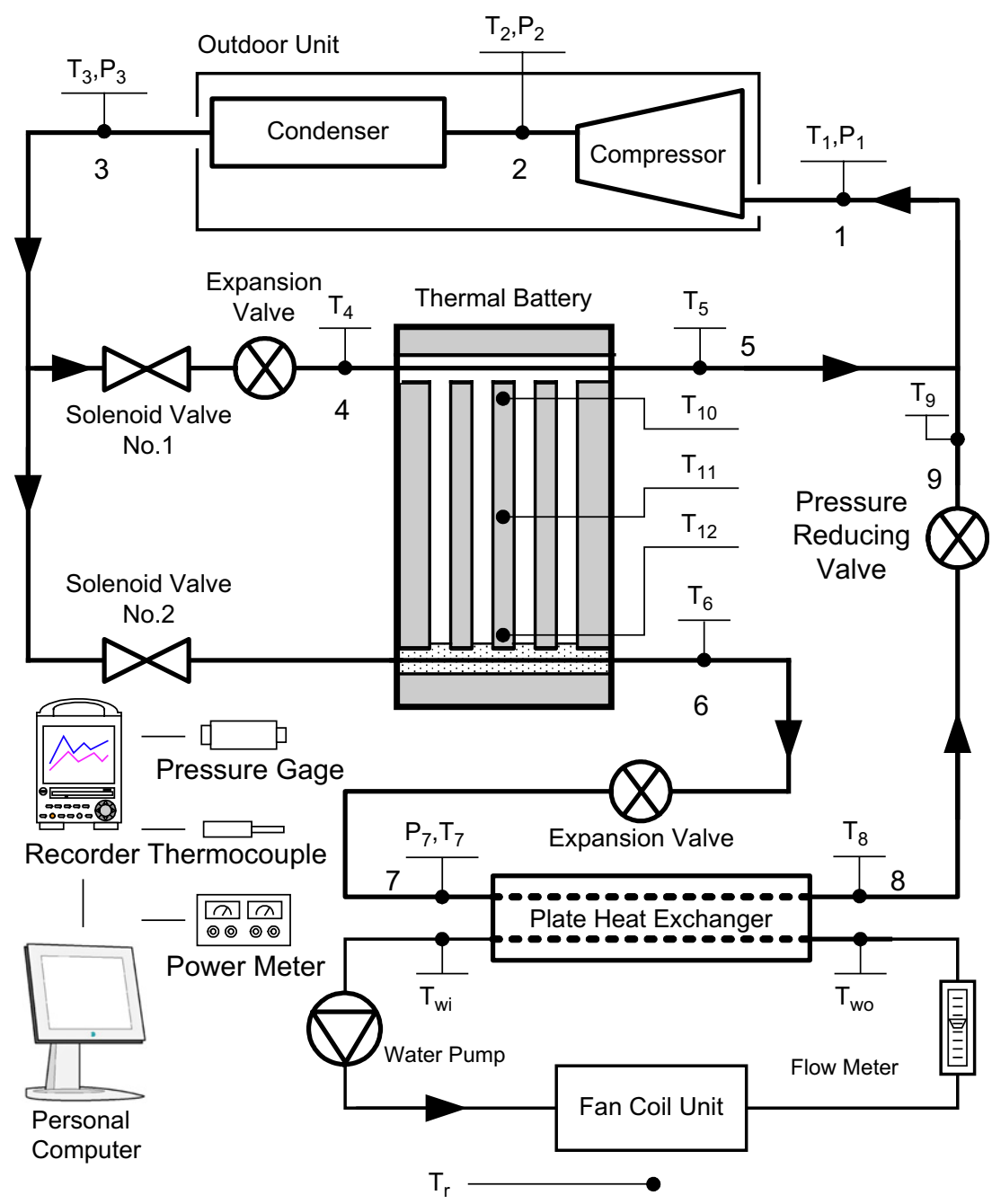

Fig. 4. Schematic of subcooled ice storage air-conditioning system and measurement apparatus.

exchanger joins the outdoor unit inlet to form a loop. The discharge heat exchanger combines the plate heat exchanger and the outdoor unit to form another loop.

The cooling energy provided by the outdoor unit is transferred from the plate heat exchanger to the fan-coil unit by water circulation. The pressure-reducing valve is installed in the outlet of refrigerant side of the plate heat exchanger to reduce the pressure of the refrigerant leaving from the plate heat exchanger. One expansion valve is set at the charge heat exchanger inlet and the other is set in the outlet of the discharge heat exchanger. The solenoid valves are set at the inlet of the charge and discharge heat exchangers of the thermal battery, respectively, to control the direction of the refrigerant leaving the outdoor unit.

Fig. 5 illustrates the pressure-enthalpy diagram of the subcooled ice storage air-conditioning system, in which the system operates in three modes: charge, discharge, and simultaneous charge and discharge modes. When the

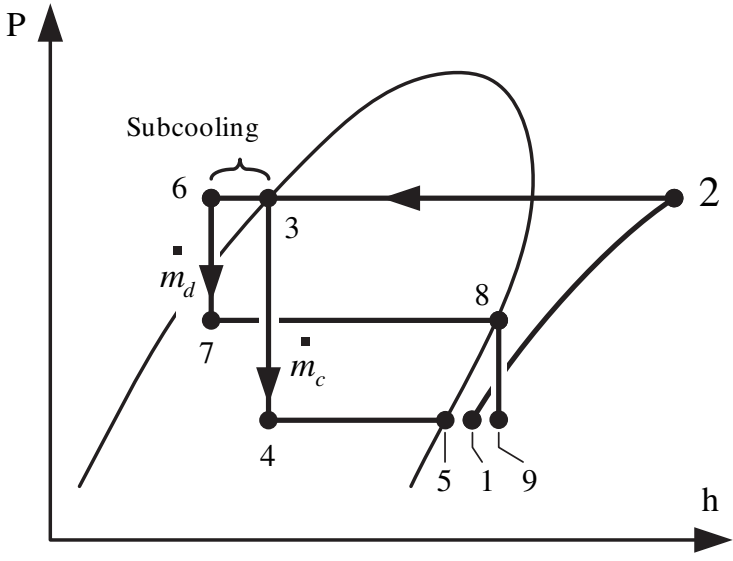

Fig. 5. Pressure-enthalpy diagram of subcooled ice storage airconditioning system. 
solenoid valve no. 1 is opened, the system operates in the charge mode. The refrigerant leaves the condenser at state 3 , and then undergoes expansion process. The refrigerant leaves the expansion valve as low temperature, low quality vapor, and then enters the thermal battery to store the cold energy. The refrigerant leaves the thermal battery at state 5 as a saturated vapor, and returns to the compressor to complete the charge cycle at state 1 .

By opening the solenoid valve no. 2, the system operates in the discharge mode. The refrigerant leaves the condenser at state 3 as high-temperature saturated liquid, and is subcooled by the thermal battery. The refrigerant leaves the thermal battery at state 6 and undergoes expansion process to be low temperature, low quality vapor. Then the vapor enters the plate heat exchanger and absorbs the cooling load of the room and undergoes a pressure-reducing process. Then the refrigerant returns to the compressor at state 9 as a superheated vapor to complete the discharge cycle.

The simultaneous charge and discharge modes are initiated when both the solenoid valves nos. 1 and 2 are opened. In such event, the system can manage the energy automatically based on the cooling capacity and the cooling load. When the cooling capacity of outdoor unit is greater than the cooling load, most of the refrigerant leaving from outdoor unit will pass the charge heat exchanger to store cold energy. The remaining refrigerant flows into the discharge heat exchanger and absorbs energy from the charge heat exchanger to cool the refrigerant. If the cooling capacity is less than the required load, small portion of refrigerant will flow into the charge heat exchanger to cool the refrigerant inside the discharge heat exchanger and most of the refrigerant will pass the discharge heat exchanger to absorb the stored cold energy in the storage tank. If the cooling capacity is equal to the load, all refrigerant will pass the discharge heat exchanger and supply the cold energy to meet the load requirement without using the stored energy in the thermal battery.

The thermal battery can shift the need of thermal energy from high cooling load to the low one. The designer can choose the capacity of outdoor unit to meet the average cooling load rather than the maximum load. Besides, the outdoor unit can operate at full load all the time due to the energy management of the thermal battery. This gives the best performance of the outdoor unit, and contributes to reduce the power consumption under the same cooling load [4]. The thermal battery subcools the discharged refrigerant of the outdoor unit before the refrigerant undergoes expansion process and let the air-conditioning system to provide more cooling capacity and higher COP than the system without the thermal battery.

\section{Experimental investigations}

In this paper, two experiments are developed to discuss the thermal performance of the ice storage air-conditioning system using thermal battery as a subcooler. In the first experiment, the thermal behavior of the energy storage material, water, in the thermal battery under different charge temperatures is investigated. Applying the result from the first experiment, the thermal performance of the subcooled ice storage air-conditioning system operating in simultaneous charge and discharge modes under various cooling loads is experimentally described. This study also examines the variation of the refrigerant mass flow rate of the charge and discharge heat exchangers of the thermal battery.

Water is used as the energy storage material in the present article because of the advantages of water, such as high latent heat, stable chemical property, easy acquisition and compatibility with the material of the air-conditioning system. However, one of the most serious problems with the use of water is the supercooling phenomenon occurring in the solidification of water during the charge process [5]. To store the thermal energy in the form of latent heat, the charge temperature of the thermal battery must be lower than the water nucleation temperature. This tends to cause a decline in the COP of the air-conditioning system. In order to ensure the latent energy storage, the highest charge temperature, which can induce the nucleation process of the water, will be experimentally obtained in this study.

Fig. 4 demonstrates the schematic of the experimental apparatus used in the experiment. The thermal battery comprises a storage tank, fin tubes and two double-pipe heat exchangers. The storage tank is made of $3 \mathrm{~mm}$ thick stainless steel plates. In the storage tank, 12 rows of copper fin tubes with 18 fins per inch are mounted. Twelve double-pipe heat exchangers, connected at the top and bottom of the storage tank, combine the fin tubes to form the two-phase closed thermosyphon. The length, width, and height of the thermal battery are $0.85 \mathrm{~m}$, $1.38 \mathrm{~m}$, and $0.745 \mathrm{~m}$, respectively. Three hundred and sixty kilogram of pure water is used inside the storage tank, and working fluid of the thermosyphon is R-22. Insulation material at the outside of the storage tank prevents heat losses during the experiment. The nominal cooling capacity of the outdoor unit is $15.5 \mathrm{~kW}$, and the refrigerant of the outdoor unit is also R-22. This study sets the room temperature at $25^{\circ} \mathrm{C}$ and water flow rate of the water pump at $95 \mathrm{lpm}$.

Fig. 4 also shows the measuring apparatus used in this study. The primary property of measurement point is the enthalpy, which can be obtained by the measured temperature and pressure. Temperature measurement utilizes $\mathrm{T}$ type thermocouples includes nine measurement locations for the refrigerant, in which, $T_{1}, T_{2}$ and $T_{3}$ for the inlet and outlet of the compressor and the outlet of the condenser, respectively; $\mathrm{T}_{4}, \mathrm{~T}_{5}$ and $\mathrm{T}_{6}$ for the inlet and outlet of the charge heat exchanger and the outlet of discharge heat exchanger, respectively; $\mathrm{T}_{7}$ and $\mathrm{T}_{8}$ for inlet and outlet of the plate heat exchanger, respectively; $\mathrm{T}_{9}$ for outlet of the pressure-reducing valve. The water temperature distributions are measured from $\mathrm{T}_{10}, \mathrm{~T}_{11}$ and $\mathrm{T}_{12}$. The water temperature of the inlet and outlet of the plate heat exchanger at water side are obtained by two thermocouples $\mathrm{T}_{\mathrm{wi}}$ and $\mathrm{T}_{\mathrm{wo}}$.

Four pressure gages within $3 \%$ accuracy determine the refrigerant pressure set at the same location of $\mathrm{T}_{1}, \mathrm{~T}_{2}, \mathrm{~T}_{3}$ 
and $\mathrm{T}_{7}$. This article assumes that the pressure at the points 1 , 4, 5 and 9 are equal, since the pressure loss caused by the piping friction is negligible. For the same reason, the pressure at the points 3 and 6 are equal, so do the points 7 and 8. The water flow rate of the plate heat exchanger is measured by flow meter. All the data are collected by a recorder and calculated by a personal computer.

The energy balance equation of the ice storage airconditioning system can be expressed as:

$\dot{Q}_{\mathrm{a}}=\dot{Q}_{\mathrm{b}}+\dot{Q}_{1}$

The cooling capacity provided by the outdoor unit, $\dot{Q}_{\mathrm{a}}$, is equal to the cold storage rate in the thermal battery, $\dot{Q}_{\mathrm{b}}$, and cooling load of the room, $\dot{Q}_{1}$. Cold storage rate can be obtained from the temperature drop of the water, $\Delta T_{n, t}$, and mass of the ice, $m_{\mathrm{s}}$, as shown by the following equation

$\dot{Q}_{\mathrm{b}}=\frac{1}{\Delta t}\left\{\left[\sum_{n=10}^{12} M_{n} C_{\mathrm{p}} \Delta T_{n, t}\right]+\left(m_{\mathrm{s}, t+\Delta t}-m_{\mathrm{s}, t}\right) h_{\mathrm{e}}\right\}$

where

$\Delta T_{n, t}=\left(T_{n, t}-T_{n, t+\Delta t}\right)$

The first term in the RHS of Eq. (2) is the sensible cold storage rate and the second term indicates the latent heat storage rate. The mass of ice, $m_{\mathrm{s}, t}$, can be calculated from the water level height, $H_{\mathrm{w}}$, in the storage tank.

$m_{\mathrm{s}, t}=L_{x} L_{y}\left(H_{\mathrm{w}, t}-H_{\mathrm{w}, t=0}\right)\left(\frac{\rho_{\mathrm{s}} \rho_{\mathrm{w}}}{\rho_{\mathrm{w}}-\rho_{\mathrm{s}}}\right)$

The ice fraction, $\beta$, is defined as the mass ratio of ice to water,

$\beta=\frac{m_{\mathrm{s}}}{M}$

The cooling load $\dot{Q}_{1}$ may be evaluated from the water temperature difference between inlet and outlet of the plate heat exchanger

$\dot{Q}_{1}=\dot{m}_{\mathrm{w}}\left(T_{\mathrm{wi}}-T_{\mathrm{wo}}\right)$

The refrigerant mass flow rate of the discharge heat exchanger, $\dot{m}_{\mathrm{d}}$, may be obtained as

$\dot{m}_{\mathrm{d}}=\frac{\dot{Q}_{1}}{h_{8}-h_{7}}$

The refrigerant mass flow rate of the charge heat exchanger, $\dot{m}_{\mathrm{c}}$, can be determined from the energy balance in the thermal battery,

$\dot{m}_{\mathrm{c}}=\frac{\dot{Q}_{\mathrm{b}}-\dot{m}_{\mathrm{d}}\left(h_{3}-h_{6}\right)}{h_{5}-h_{4}}$

According to the uncertainty analysis proposed by ISO standard [6], the uncertainties in percentage of cooling capacity, cooling load and cold storage rate of the thermal battery are $\pm 7.6 \%, \pm 4.3 \%$ and $\pm 4.7 \%$, respectively.

\section{Results and discussion}

Fig. 6 shows temperature distribution of water in the storage tank during charge process for different charge temperatures $\left(-5{ }^{\circ} \mathrm{C},-7{ }^{\circ} \mathrm{C}\right.$ and $\left.-9{ }^{\circ} \mathrm{C}\right)$. During the experiment, water is cooled from sensible heat storage to latent heat storage. In the form of sensible energy storage water at different levels has almost the same temperature profiles, which means thermal stratification does not appear in the storage tank. This is due to the fact that film evaporation occurs inside the thermosyphon and keeps the water temperature uniform. It also means that the thermal energy coming from the charge heat exchanger can be spread to and stored in water by the superior heat transfer rate of film evaporation. This makes the system store cold energy more efficiently, and enhances charge density of the thermal battery.

Fig. 6 also indicates that the nucleation occurs for the cases of $-7{ }^{\circ} \mathrm{C}$ and $-9{ }^{\circ} \mathrm{C}$, while the supercooling appears when the charge temperature is $-5^{\circ} \mathrm{C}$. For the cases of $-5{ }^{\circ} \mathrm{C}$, the temperature of water is cooled from $21^{\circ} \mathrm{C}$ to $0{ }^{\circ} \mathrm{C}$, which stores the energy by sensible heat. As further cooling occurs, freezing does not occur at the water freezing temperature $\left(0{ }^{\circ} \mathrm{C}\right)$. Water below $0{ }^{\circ} \mathrm{C}$ is called supercooled and is a state of meta-stable. In this case thermal energy can only be stored in the form of sensible heat. To store the energy in the form of latent heat, the entrance temperature of the flowing fluid must be lower than the water nucleation temperature (about $-6{ }^{\circ} \mathrm{C}$ ). For the case of $-7{ }^{\circ} \mathrm{C}$ and $-9{ }^{\circ} \mathrm{C}$, the ice nucleation occurs and thin plate-like crystal grows into the supercooled region. During the crystal growth process, latent heat released from the crystal is consumed by supercooled water. The water temperature returns to its freezing temperature. As the charge process is continued, the solid ice will form around the fin tubes and the cold is stored by latent energy.

Fig. 7 illustrates the ice fraction variation for different charge temperatures. For the case of $-9{ }^{\circ} \mathrm{C}$, water stores the cold energy in the form of sensible energy, such that the ice fraction is zero during the first half hour until the nucleation is induced and the ice fraction is initiated. As more cold energy is stored in the thermal battery, the ice fraction increases gradually, so does the thickness of the ice covering on the outside of the fin tubes. This causes greater thermal resistance and delays the ice formation. The total time required for complete ice formation is about $4 \mathrm{~h}$ when the charge temperature is $-9{ }^{\circ} \mathrm{C}$. For the case of $-7^{\circ} \mathrm{C}$, the nucleation occurs at $45 \mathrm{~min}$ after the experiment began and the total time required for complete ice growth is $6 \mathrm{~h}$. In the case of $-5^{\circ} \mathrm{C}$, the ice fraction maintains zero during all experimental period. Only sensible energy storage can be observed in this case. Therefore it is necessary to control the charge temperature lower than $-6{ }^{\circ} \mathrm{C}$ to ensure that cold is stored by latent heat. 
(a)

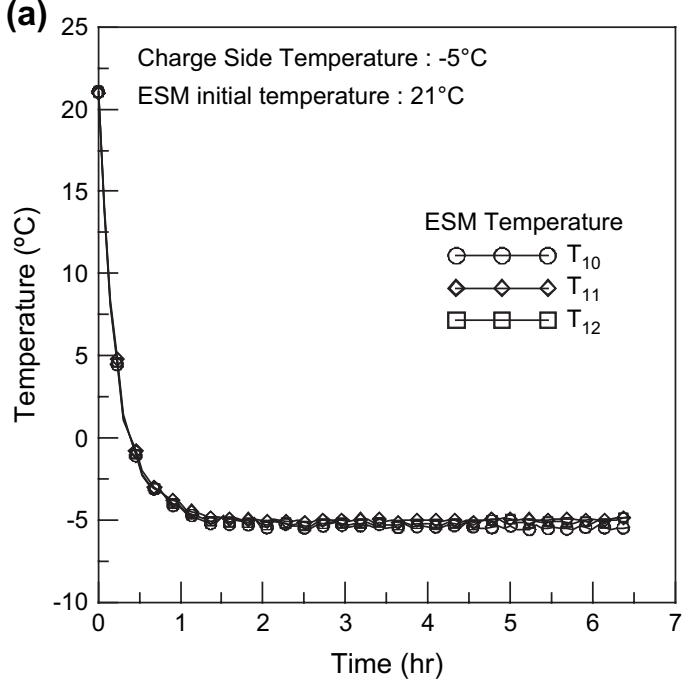

(b)

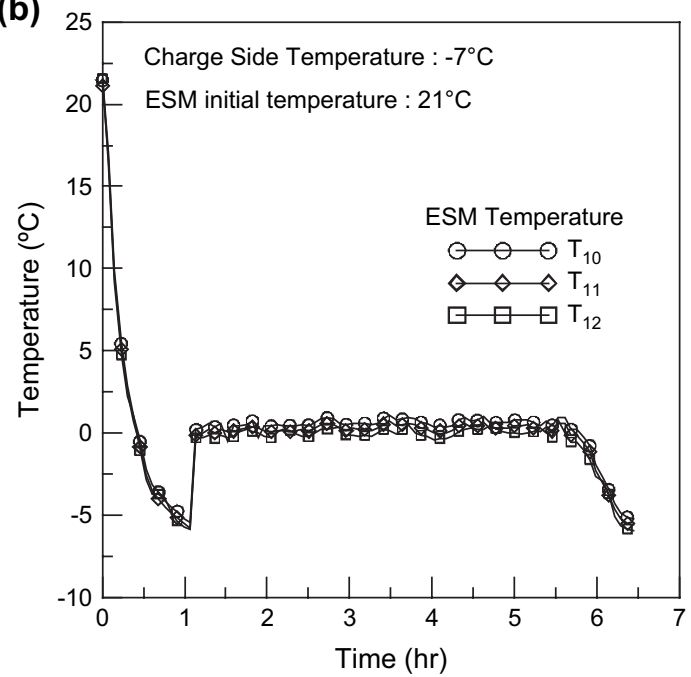

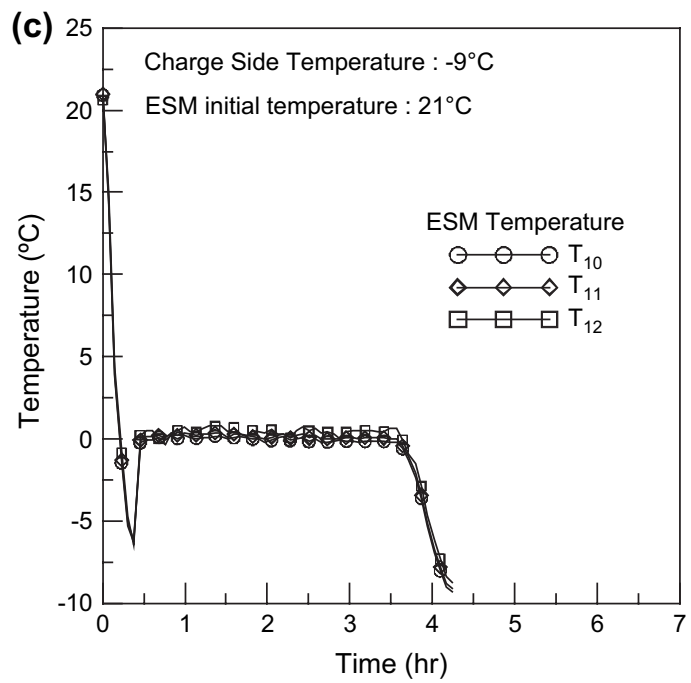

Fig. 6. Temperature distribution of water during the charge process for different charge temperatures (a) $-5^{\circ} \mathrm{C}$, (b) $-7^{\circ} \mathrm{C}$, and (c) $-9{ }^{\circ} \mathrm{C}$.

Fig. 8 shows the variation of the cooling load, the outdoor unit cooling capacity and cold storage rate of the thermal battery when the subcooled ice storage air-conditioning system operates in simultaneous charge and discharge modes. The present experiments can be divided into three regions. In region I, the cooling load is less than the cooling capacity, extra cold energy is stored by the thermal battery, such that the cold storage rate in the thermal battery is positive. In region II, the cooling load is greater than the cooling capacity, thermal battery releases the stored energy to supply the need of cooling load, and the cold storage rate is negative. In region III, the cooling load is smaller than the cooling capacity and the cold storage rate of the thermal battery becomes to be positive again.

The cooling capacity supplied by the outdoor unit is maintained almost constant and equals to the nominal capacity of the outdoor unit $(15.5 \mathrm{~kW})$ during the first ten hours of the experiment. This indicates that the thermal battery can automatically manage the charge and discharge of the cold energy and let the outdoor unit operates at full load, in which the outdoor unit gives the best performance. After $18 \mathrm{~h}$, the decreasing cooling capacity results from the low cooling load and cold storage rate caused by greater thickness of the ice formation on the outside of fin tubes. The maximum cooling capacity of the subcooler ice storage air-conditioning system is $19.8 \mathrm{~kW}$, which is $28 \%$ higher than the nominal capacity of the outdoor unit.

Fig. 9 demonstrates variation of the room temperature, the water temperature and the ice fraction of the thermal battery. Since the thermal battery stores cold energy in region I, water temperature drops to its nucleation temperature at $10 \mathrm{~h}$ and then the ice forms. In region II, thermal battery releases the stored energy, and the ice melts initially. The ice melts completely at $12 \mathrm{~h}$, then water supplies the cold in the 


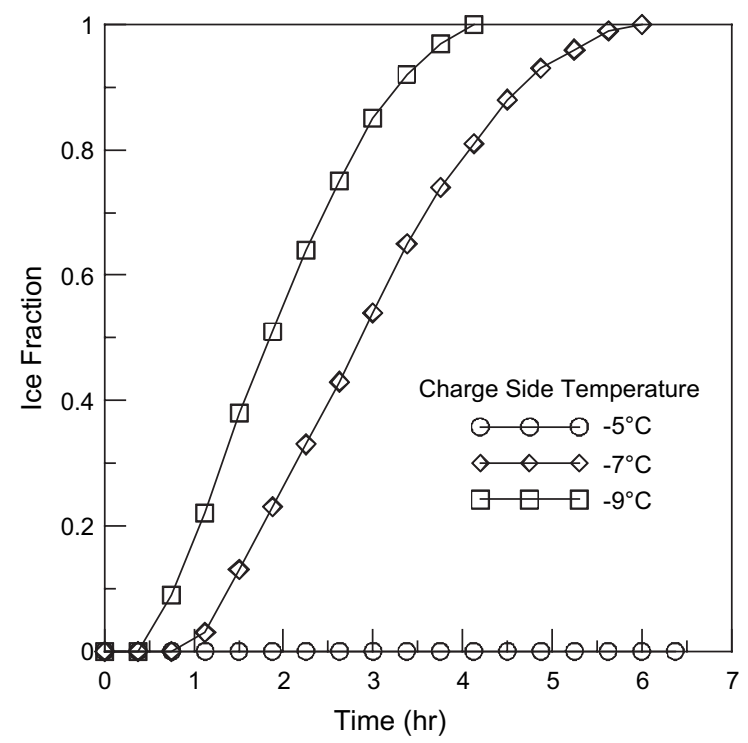

Fig. 7. Ice fraction variations under different charge temperatures.

form of sensible energy to the need of cooling load. Water temperature increases gradually and reaches to its maximum of $22.5^{\circ} \mathrm{C}$ at the end of region II. In region III, the water temperature drops gradually till the nucleation occurs at $18 \mathrm{~h}$. Then the extra cold energy is stored in the form of latent energy and the ice fraction increases. The room temperature is maintained at $25 \pm 0.3{ }^{\circ} \mathrm{C}$ during the experiment period. This indicates that the proposed subcooled ice storage air-conditioning system can give a constant temperature environment.

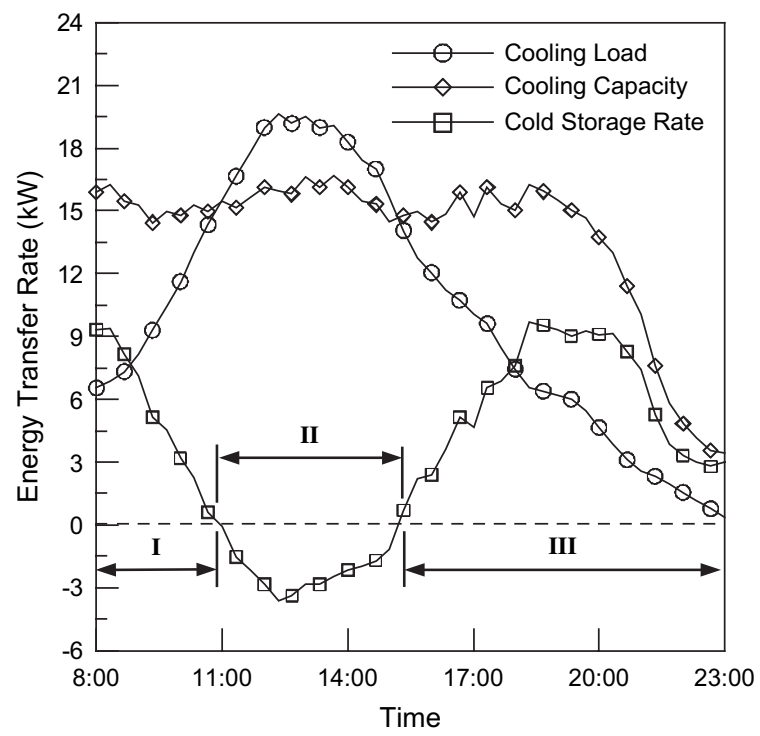

Fig. 8. Cooling load, cooling capacity and cold storage rate of the thermal battery.

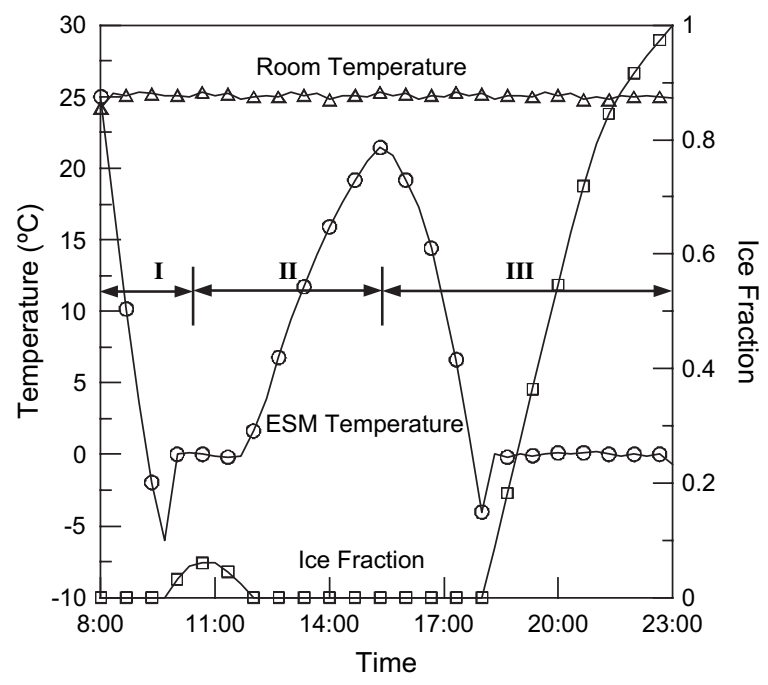

Fig. 9. Variation of the room temperature, the water temperature and the ice fraction of the thermal battery.

Fig. 10 depicts the variation of cooling load and refrigerant mass flow rate of the charge and discharge heat exchangers of the thermal battery. The charge and discharge refrigerant mass flow rates show similar trend with the cold storage rate and the cooling load, respectively as shown in Fig. 8. In region I, more and more refrigerant flows into the discharge heat exchanger rather than the charge heat exchanger as the cooling load is increasing. In region II, almost all the refrigerant passes the discharge heat exchanger since the cooling load is greater than the cooling capacity. In region III, lower cooling load induces decreasing refrigerant

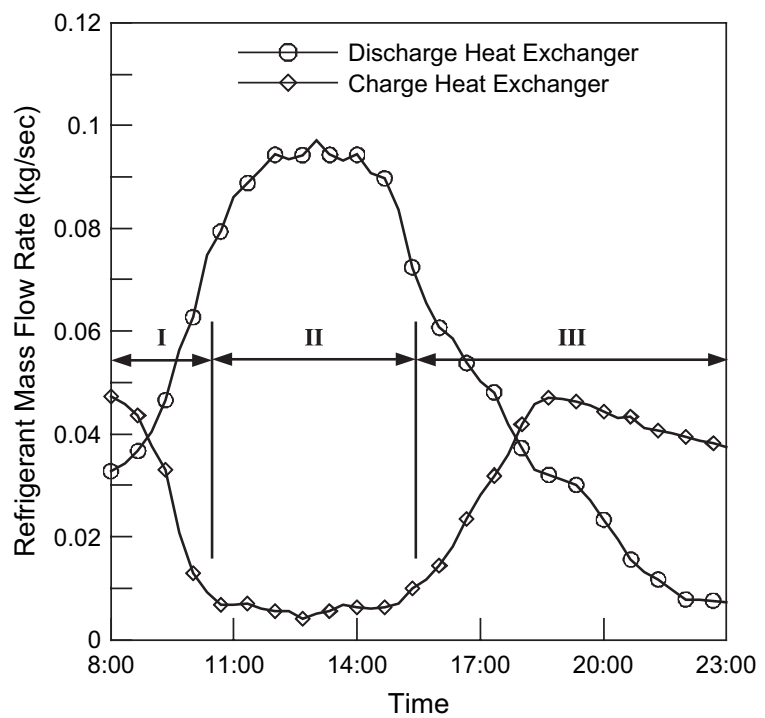

Fig. 10. Charge heat exchanger and discharge heat exchanger of refrigerant flow rate and the cooling load. 


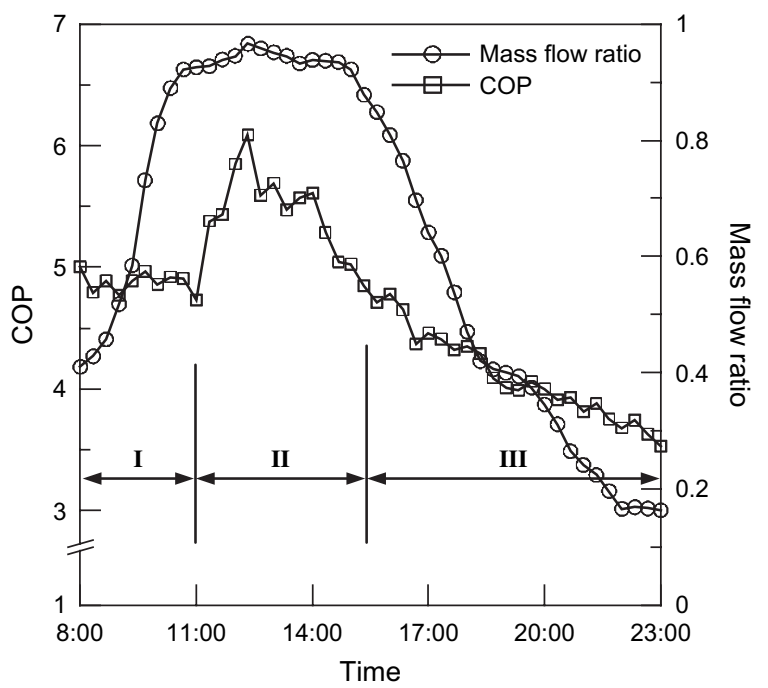

Fig. 11. COP of the subcooled ice storage air-conditioning system and the mass flow ratio of the refrigerant.

flow rate of the discharge heat exchanger. The charge refrigerant mass flow rate is related to the variation of the cold storage rate. It shows that the proposed ice storage air-conditioning system can manage the cold storage by adjusting the distribution of the refrigerant flow from cooling capacity and cooling load without any electrical controller included.

Fig. 11 shows the COP of the subcooled ice storage airconditioning system and the mass flow ratio of the refrigerant, which are calculated from the experimental data of Fig. 10. Since the system operates in simultaneous charge and discharge modes, the COP of the system can be expressed as

$\mathrm{COP}=\frac{(1-r)\left(h_{5}-h_{4}\right)+r\left(h_{8}-h_{7}\right)}{\left(h_{2}-h_{1}\right)}$

where $r$ is the mass flow ratio of the refrigerant,

$r=\frac{m_{\mathrm{d}}}{m_{\mathrm{c}}+m_{\mathrm{d}}}$

As seen in Fig. 11, the mass flow ratio of the refrigerant lies in the range between 0 and 1, depending on the cooling load and the cooling capacity. At region I the cooling capacity of the system is greater than the cooling load. Extra cold energy is stored in the thermal battery. The mass flow ratio increases from 0.41 to 0.93 as the cooling load changes from $6.2 \mathrm{~kW}$ to $15.0 \mathrm{~kW}$. At this stage the subcooled ice storage air-conditioning system operates with a constant $\mathrm{COP}$ of 4.8. At region II since the cooling load is higher than the cooling capacity, most of the refrigerant enters the discharge heat exchanger of the thermal battery. The mass flow ratio of the refrigerant changes from 0.93 to 0.96 . The COP shows a similar trend with the cooling load, the best of which is 6.1. As the cooling load is decreasing at region III, most refrigerant flows through the charge heat exchanger of thermal battery. The charging process decreases the evaporating pressure of the system in order to solidify the water inside the storage tank, which lowers the system COP to 3.5 at the end of the experiment. The mean COP of the system covering from region I to III is 4.5. If the system is operated without the subcooler, the COP of the system is 3.9 at the conditions of $50{ }^{\circ} \mathrm{C}$ condensing temperature and $5{ }^{\circ} \mathrm{C}$ evaporating temperature. For the case of ice storage, the system $\mathrm{COP}$ is 3.1 while the condensing and evaporating temperatures are $50{ }^{\circ} \mathrm{C}$ and $-7{ }^{\circ} \mathrm{C}$, respectively. It is obvious that the subcooled ice storage air-conditioning system benefits not only greater cooling capacity but also better performance by adopting the thermal battery as the subcooler.

\section{Conclusions}

This paper provides a thermal battery allowing operation of charge, discharge and simultaneous charge and discharge modes. Application of thermal battery as a subcooler in the ice storage air-conditioning system is demonstrated. The subcooled ice storage air-conditioning system can automatically adjust the refrigerant mass flow rates at the charge and discharge heat exchangers, depending upon the energy contents of charge and discharge sides. In addition to providing an enhanced COP technology through subcooling of hightemperature condensate refrigerant, it also balances the cooling load to permit the outdoor unit operating at fullload condition.

\section{References}

[1] ASHRAE, ASHREA Handbook - HVAC Systems and Equipment, ASHRAE Inc., Atlanta, 2004.

[2] ASHRAE, ASHREA Handbook - HVAC Applications, ASHRAE Inc., Atlanta, 2003.

[3] J.J. Chieh, S.J. Lin, S.L. Chen, Thermal performance of cold storage in thermal battery for air conditioning, Int J Refrigeration 27 (2004) 120-128.

[4] S.K. Wang, Handbook of Air Conditioning and Refrigeration, McGraw-Hill, 1993.

[5] S.L. Chen, T.S. Lee, A study of supercooling phenomenon and freezing probability of water inside horizontal cylinders, Int J Heat Mass Transfer 41 (1998) 769-783.

[6] Guide to Expression of Uncertainty in Measurement, ISO, 1995 (corrected and reprinted). 